\title{
PARTICIPATION IN EDUCATION AMONG OLDER PEOPLE
}

\author{
Marshall J. Graney
}

\begin{abstract}
National random sample data on 4254 people in four adult age categories were analyzed with regard to enrollments in different kinds of education settings, enrollment motives, and barriers to enrollment. Further analysis compared participants to nonparticipants. Most adult enrollments were at the college or university level before age 40 , in other settings thereafter, and instrumental motives were predominant across the lifespan. Lack of time and interest were major barriers to enrollment among older people, and those enrolled generally had higher prior educational attainments, were younger, and lived in urban or suburban locations.
\end{abstract}

The smaller birth cohorts that began in the United States in the late 1950's have meant that institutions of higher education must draw their traditional freshman enrollments from a shrinking pool of high school graduates in the 1970s and beyond. At the same time that this pool of constituents of college freshman classes shrinks, the proportion of people aged 65 years and older in the population has been projected to increase. Some adjustments to accomodate these demographic changes have already begun to take place among many institutions of higher education (Timmermann, 1978; Weinstock, 1978). These developing changes in programs and curriculum to accomodate more older students can be guided by the educational interests of older people, and a number of studies have examined these interests and correlates of interests. Most studies have carefully analyzed data from smaller, specialized, or geographically restricted samples, although some findings have been established which are

Marshall J. Graney is Associate Professor of Sociology, Department of Sociology, Wayne State University, Detroit, Michigan, 48202, and Faculty Affiliate of the Wayne State University-University of Michigan Institute of Gerontology. This research was supported in part by a grant from the Institute of Gerontology.

Alternative Higher Education, Vol. 5(1), Fall 1980 
based on large scale national random samples, as noted in later sections of this report. The purpose of research reported here was to review previous findings and to examine their generalizability and develop additional detailed knowledge about the educational interests and participation of older people as shown in national random sample data.

\section{EDUCATIONAL INTEREST AND PARTICIPATION}

\section{General Interest}

Findings about the percentage of the older population who express interest in further education vary widely, and this can be explained in terms of other characteristics of the samples and the kinds of courses of study considered in questionnaires and interviews. At one extreme, Hendrickson and Barnes (1967) found that only one percent of an Ohio sample of 2,307 persons aged 65 years or older were interested in taking on-campus college or university courses; and at the other extreme the Central Bureau for the Jewish Aged (1971) found that almost 75 percent of a New York sample of 955 persons aged 65 years or older were willing to attend educational or cultural programs at least once a week. In other findings Graney \& Hays (1976) found that 26 percent of a Kansas sample of 424 persons aged 62 years old or older expressed interest in taking college-level courses. Data on a Missouri sample of "active elderly" showed that 22 percent were interested in participating in further education, if there were no tuition costs involved (Phelps, Endreson, and Peterson, 1976).

\section{Participation}

Some serious issues are involved in transforming older people's general interests in education into enrollments, and these issues have been addressed and reviewed by Marcus (1967). Like findings on interest, statistics about participation vary widely from sample to sample. At one extreme, Uphaus (1972) found that 71 percent of an Arizona sample of 102 retired people aged 60 and over had actually participated in some form of postretirement educational endeavor. One reason this statistic may be so high is that the sample was composed entirely of college graduates. A radically different statistic is available in the finding of Peterson (1974), who found in U.S. Bureau 
of the Census data that as of 1969 only 1.6 percent of people aged 65 or older were involved in some form of further education.

Michigan data on persons aged 65 years and older showed that 85 percent had not participated in any formal educational activity within the preceeding five years (Michigan, 1975), and data on 244 Wisconsin residents aged 65 and older showed that 91 percent had not been involved in any kind of formal education program in the preceeding two years (Racine, 1978). Harris and associates (1975) found that 5 percent of the population aged 55 to 64 were enrolled, as compared to 2 percent among those aged 65 or older in national random sample data. This indicates a probable increase in older people's participation in further education, because earlier U.S. Bureau of Census data placed enrollment figures at 3 percent among those aged 60 through 74, and found one percent participation among those aged 75 or older (1958).

Although enrollments of older people are found in a variety of institutional settings, many enroll in colleges and universities. Weinstock (1978) found that 3 percent of college and university students are age 55 or older, accounting for 1.7 million students nationwide. Most older people prefer at-home courses to lecture or seminar formats (Weinstock, 1978), probably because the lower average level of previous educational attainment in the older population means that they are less familiar and comfortable with more formal education settings than is the situation with younger people. However, at-home courses were offered to older people by only 17 percent of three hundred fifty institutions of higher education responding to a national survey (DeCrow, 1978). Other participation preferences of older people include daytime classes over evening, dispersed neighborhood learning centers over central campus (Central Bureau, 1971), and age concentrated over age-dispersed classmates (Central Bureau, 1971; Peterson, 1974).

\section{Settings}

According to Harris and associates most (60 percent) students under the age of 65 are enrolled at colleges or universities (1975). In contrast, only 24 percent of students aged 65 and over were found to be taking classes at colleges or universities. Many (26 percent) of those 65 and over take courses at a church, 19 percent attend an adult education facility, 10 percent study through correspondence and 21 percent reported other kinds of enrollments. In comparison, among students 18 through 64 only 3 percent take courses at a church, 5 percent through correspondence, 7 percent at a high school, 12 percent at an adult education facility, and 16 percent elsewhere. In a Wiscon- 
sin study, 9 percent of those 65 or over were found to participate in some form of further education (Racine, 1978). The educational settings were distributed as follows: 0.8 percent of the over 65 population were enrolled at a college or university, 2.5 percent attended classes at a Senior Center, 2.9 percent were enrolled in adult education, and 3.7 percent reported other education settings.

\section{Subject Area Interests}

One third of the nation's colleges and universities offered some form of education program for older people by 1977 (Timmermann, 1978). In these offerings a mixture of courses and programs has been needed because of the heterogeneity of interests within the older population (Weinstock, 1978). Many courses for older people depart from traditional college offerings, and a national survey of colleges and universities found that academic courses formed the most important part of the curricula for older people in less than half of these institutions of higher education (DeCrow, 1978). Numerous studies have found that those older people who do express interest in higher education are diverse with respect to the specific kinds of courses in which they are interested (e.g., Hendrickson, 1973; or Graney \& Hays, 1976). Nevertheless, despite the diversity of interest areas, large numbers of specific courses of study can be grouped under two broad headings: instrumental courses, which are concerned with building knowledge and skills; and expressive courses, which are taken for intrinsic reasons such as using time in an entertianing way, or sharing pleasant experiences with other people (Londoner, 1971).

Older people's subject area interests found in smaller, specialized, or geographically restricted samples vary widely. Hendrickson \& Barnes (1967) found numerous interests. When 2307 persons age 65, or over were given 96 items from which to choose, the most popular items included religion, problems of aging, gardening, travel and physical fitness. Hendrickson (1973) later reviewed other research on older people's subject area interests and suggested that the findings document the following hierarchy of interests: (1) religion; (2) problems of aging; (3) physical fitness; (4) leisure activities; (5) the arts; (6) public affairs; and (7) practical problems. Graney \& Hays (1976) developed similar findings, except that they found no interest in special courses for older people and a substantial amount of interest was expressed for traditional arts and sciences courses (42 percent) and crafts (32 percent), with vocational ( 13 percent) and business ( 6 percent) courses less frequently mentioned by older people. 
Uphaus (1972) found greatest interest in courses related to problems of aging ( 31 percent), closely followed by academic subjects ( 27 percent) and arts and crafts ( 25 percent), with few choosing vocational courses (3 percent). Harris and associates (1975) reviewed interest areas among enrolled older people aged 65 and over, and found that 76 percent wanted to expand general knowledge about some field or hobby, 39 percent wanted to make good use of time, 28 percent wanted to be with other people, 6 percent wanted job skills, and 2 percent gave other reasons. Sarvis (1973) found greatest interest in art (38 percent), constructive crafts, consumerism, languages, and "gray" power, and least interest in courses intended to enhance coping skills (especially in communication and computation) and in basic education courses (0.4 percent) in a state of Washington sample of 189 persons aged 55 years old or older. Hiemstra's (1972) analysis of eighty-six retired persons, among whom the women's average age was 70.4 and the men's 71.4, who participated in educational activities in residential centers concluded that instrumental motives were paramount in the educational interests of these older people. The Michigan (1975) sample of older people who had participated in formal education endeavors within the preceeding five years showed that most of their participation was in non-academic courses such as arts and crafts.

\section{Factors Affecting Participation}

A number of different factors affect older people's interest and participation in further education activity, including the older person's age, sex, race, past educational attainment, rural/urban place of residence, health, financial status, self concept, and other factors. Research findings on these several factors are reviewed below.

Age. Uphaus (1972) found that participants in postretirement education were, on the average, younger, better educated, had higher income, and sustained better health, than nonparticipants. Carp et al. (1974) found that the pattern of declining interest in education in association with advancing age was especially pronounced after age 55. Harris and associates (1975) found further regression past age 65. Graney \& Hays (1976) found a significant correlation of $\mathbf{r}=-0.20$ between older people's age and interest in further education.

Sex. Goodrow (1976) found that older women cited a smaller average number of barriers to participation in higher education than did older men. 
Race. Jackson \& Wood (1976) found that blacks were more likely to plan to take courses, and also more likely to actively participate in further education, in comparison to whites in a sample of 2400 persons aged 65 and over.

Education. Graney \& Hays (1976), Harris, et al. (1975), Hiemstra (1972), and Uphaus (1971), have found direct correlations between level of prior educational attainment and either interest in further education or actual enrollment among older people. For example, in analysis of data on older people Harris and associates (1975) found enrollments among college graduates ( 7 percent) to be more than double those of high school graduates ( 3 percent).

Rural/Urban. Carp, et al. (1974) found that urban older people were more likely to be active in educational endeavors.

Health. Poor health can be a major barrier to participation in further education at any age, and this condition is increasingly likely among the "old-old." In Wisconsin data 13 percent cited poor health as a barrier to further education (Racine, 1978).

Financial. Dollar costs have been identified as a barrier to older people's participation in further education in a number of studies. Its importance has been emphasized by Graney \& Hays (1976), where dollar costs were cited as a barrier by 36 percent of persons expressing interest in higher education. Phelps, et al. (1976) also found the costs of tuition and fees to be major factors. Other studies have identified dollar costs as a factor of lesser importance (Hiemstra, 1972, cited by 7 percent; Racine, 1978, cited by 2 percent).

Self Concept, Activity, Affect Balance. Disinterest in further education per se may sometimes be attributed to a negative self concept which is expressed by the idea that someone is "too old to learn." This fear of failure in educational endeavors is an expression of disengagement: the inverse of the higher morale, positive life satisfaction, and zest for life that characterizes many older people. Several kinds of positive well-being have often been associated with happiness on the one hand, and a general activity factor on the other (Graney, 1975). Among older people who expressed disinterest in higher education, a negative self-image was one of the chief factors according to research by Graney \& Hays (1976): being too old to learn was cited by 28 percent, and feeling out of place in the classroom was cited by 27 
percent of people who had no interest in pursuing higher education. Fear of failure ("too old," 42 percent) was also a major barrier to participation according to national sample data on people aged 55 to 60 analyzed by the Educational Testing Service and cited by Phelps, et al. (1976).

Other factors. A quite different variety of disinterest from the general disengagement from life mentioned above is apathy regarding the specific courses of study that are available and offered to older people. In Hiemstra's (1972) sample 8 percent cited this factor, and in Wisconsin data 38 percent (Racine, 1978). Graney \& Hays (1976) found that lack of interest in current course offerings was one of several variables on which there were significant contrasts between those older people who were interested in higher education and those who were not, and this factor was cited by 34 percent of those who professed no interest in further education. A number of other factors that serve as barriers to older people's participation in education have been identified, including time costs (Graney \& Hays, 1976); transportation needs (Hiemstra, 1972; Racine, 1978), and need for information on programs and courses (cited by 38 percent of older people interested in higher education, Graney \& Hays, 1976).

\section{SAMPLE AND VARIABLES}

\section{Sample}

Our analysis is based on survey data collected for the National Council on Aging by Louis Harris and associates. This survey was a multi-stage random cluster sample of households in the continental United States using sampling procedures that have been described in detail elsewhere (Harris and associates, 1975). A total of 4,254 persons were interviewed, of whom 2,797 were 65 years old or older. Oversampling within the older age categories was done to assure accurate parameter estimation for these categories, which were weighed at national sample proportions for the analysis reported here.

\section{Variables}

The analysis presented here is divided into three parts: 1) motive and place of enrollment; 2) barriers to enrollment; and 
3) enrolled/nonparticipant comparisons. All of these issues are examined in terms of chronological age; youth (18-24 years), young adult (25-39 years), middle-aged (40-54 years) and older (aged 55 and over).

Motives for enrollment are analyzed as instrumental (Campbell, et al., 1974) and expressive. Settings or places of enrollment are classified as either college (or university) or noncollege.

Seven specific barriers, and one residual barrier, to enrollment are analyzed. These are: not being interested in further education, not knowing of suitable courses, not knowing of the availability of any courses, no time, expensive, poor health, too old, and other.

Age category comparisons between enrolled and nonparticipants were based on ten variables. Five variables served as demographic measures: fine coded age, sex, race, prior educational attainment, and rural/urban residence (urban and suburban were classified as urban, others were classified as rural). Three variables served as measures of social well-being: health, financial status, and general activity. Two variables served as measures of personal attitudes: self concept and the Bradburn (1969) affect balance scale.

\section{FINDINGS}

\section{Age, Setting, and Motive}

Older people are less likely to be enrolled in educational endeavors than younger people, and the percentages of the national random sample reporting enrollments of various kinds were 34 percent among youth aged 18-24; 15 percent among young adults 25-39; 5 percent among middle-aged persons $40-54$; and 4 percent among older people aged 55 or older. The places of enrollment among enrollees also vary considerably from age category to age category, with college or university settings accounting for 68 percent of youth enrollment, 60 percent among young aduits, 41 percent among middleaged, and 30 percent among older people. A number of other important facts about age, places of enrollment, and enrollment motives are tabulated in Table 1 and reviewed below.

Instrumental Motives. There is evidence that the percent of the sample who offered reasons for enrollments that can be classified as neither instrumental nor expressive motives was not more than 5 percent of total enrollments for any age category, and this 
Table 1. Enrollment Motive by Age and Educational Setting

\begin{tabular}{|c|c|c|c|c|c|c|c|c|c|c|}
\hline \multirow{3}{*}{ Aze } & \multicolumn{9}{|c|}{ Enrol?ment Motive ( 8 eiting) } & \multirow{3}{*}{$(N)$} \\
\hline & \multicolumn{2}{|c|}{ instrutental (I) } & \multicolumn{2}{|c|}{ Betstis } & \multicolumn{2}{|c|}{ Exoresstre (3) } & \multicolumn{2}{|c|}{ Hesther Inor 8} & \multirow{2}{*}{ Total } & \\
\hline & Collez & Non-Collage & $\cos 3958$ & Non-Conferes & Colleze & Non=folierg & Coliege & Borreoliere & & \\
\hline $13-24$ years & 39 & 15 & $2 ?$ & $1:$ & 2 & 5 & 3 & 1 & 100 & $(244)$ \\
\hline $25-39$ yeats & 43 & 30 & 15 & 5 & 0 & 2 & 2 & 3 & 100 & (1?1) \\
\hline 30 - 44 years & $3 ?$ & 48 & 4 & 6 & 0 & 4 & 0 & 2 & 100 & $(\$)$ \\
\hline $55+$ years & 16 & $3^{4}$ & $\hat{z}$ & 43 & 5 & 3 & 2 & 0 & 100 & (37) \\
\hline
\end{tabular}

percent was lower for the mature age categories of middle-aged and older persons than for youthful age categories of youth and young adults. Instrumental motives figured prominently among enrollments in all age categories.

Except for the most mature age category analyzed, relatively unmixed instrumental motives were clearly the most frequent reasons for both college and non-college enrollments among participants of all ages, accounting for 54 percent of all enrollments among youth, 73 percent among young adults, 85 percent among middle-aged, and 40 percent of enrollments among older people. It is interesting to note that among youthful sample categories most of these instrumental enrollments were college enrollments ( 39 percent college versus 15 percent noncollege among youth; 43 percent college versus 30 percent noncollege among young adults), but among more mature age categories most instrumental enrollments are in noncollege settings (48 percent noncollege versus 37 percent college among middle-aged; 24 percent noncollege versus 16 percent college among older people).

Mixed Motives. Except among persons in the oldest age category, where mixed motives are predominant, a mixture of instrumental and expressive motives was much less frequently cited as a basis for enrollment than instrumental motives alone. Mixed motives are relatively more common among the youngest age category ( 34 percent) and oldest age category (51 percent) than among young adults (20 percent) or middle-aged (10 percent). Among the younger and older age categories these mixed motives tend to be expressed by college enrollments of the young ( 23 percent college versus 11 percent noncollege), but by noncollege enrollments among older people ( 43 percent noncollege versus 8 percent college). 
Expressive Motives. Although expressive motives are commonly eited among reasons for enrollments of people in all age categories, these motives are rarely sufficient to elicit enrollments unless they occur in conjunction with instrumental motives. Thus, for each age category analyzed the proportion of enrollments attributed to mixed motives was several times larger than that attributed to expressive motives only. Young adults represent the age category least frequently citing expressive motives only 2 percent, and the percent among middle-aged was similar (4 percent). However, expressive motives were more common among youth ( 7 percent) and older people (8 percent).

\section{Barriers Cited by Nonparticipants}

Persons in all age categories who were nonparticipants in educational endeavors were questioned about their reasons for nonparticipation. In their responses older people were less likely than younger people to be unsure of barriers, or to cite miscellaneous barriers. Seven specific barriers to participation were classified, recorded, tabulated, and analyzed. Among these barriers there was evidence of substantial age differences among some, but others were cited with approximately equal relative frequencies by persons in all age categories. These findings are tabulated in Table 2 and reviewed bebelow.

Reasons for nonparticipation in educational endeavors for which no substantial age differences were found were also reasons that were relatively infrequently cited by people in any age category. These barriers included the perception that the courses of study offered were not suitable, which was cited as a barrier by no fewer than 2 percent of the respondents, among people aged $40-54$, and by no more than 5 percent of the respondents, among people aged 18-24 years. Another barrier for which no substantial age difference was evident was the respondent's perception that courses were unavailable. This barrier was cited by no less than 2 percent of respondents, in age categories 18-24 and $25-39$, and no more than 5 percent of respondents, in age category 55 years and older.

Certain other barriers to participation were more likely to be cited by more mature respondents than by younger people. For example, lack of interest in further education represents such a barrier, being cited by less than 30 percent of youth or young adults, but by 40 percent of people aged 55 years or older. Similarly, poor health was cited by only one percent among youth or young adults, 8 percent among middle-aged, and 18 percent among older people. The negative self- 
Table 2. Percent Citing Various Barriers to Participation, by Age

\begin{tabular}{|c|c|c|c|c|}
\hline \multirow[b]{2}{*}{ Barter } & \multicolumn{4}{|c|}{ Age Catezory } \\
\hline & $(N=772)$ & $\begin{array}{c}25-39 \\
\left(y^{2}=1176\right)\end{array}$ & $\begin{array}{c}40-5 / 4 \\
(N=1093)\end{array}$ & $(N=5 \%$ \\
\hline Not Interested & 29 & 26 & 37 & 40 \\
\hline Courses Not Sultable & 5 & 3 & 2 & 4 \\
\hline Courses Not Availaisle & 2 & 2 & 3 & 5 \\
\hline No Thane & 32 & 51 & 45 & $2 \hat{3}$ \\
\hline Expensive & 14 & 9 & 5 & 2 \\
\hline Foor feslth & 1 & 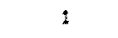 & 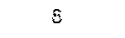 & 18 \\
\hline Too Old & 0 & 0 & 2 & \pm 6 \\
\hline Other, or Unsurs & 22 & 22 & 9 & 8 \\
\hline
\end{tabular}

conception of believing one's self to be too old for participation in further education serves as a barrier with a pattern of age distribution parallel to the barrier of poor health, with fewer than 0.5 of one percent of youth or young adults citing the problem of being "too old," 2 percent among middle-aged, and 16 percent among older people.

The perception that a person does not have time to participate in further education follows a curvilinear relationship to age. Youth (32 percent) and older people ( 23 percent) do not cite lack of time as a barrier to further education as frequently as do young adults (51 percent) or middle-aged (45 percent). Dollar expense is less of a problem for older age categories.

\section{Participant-Nonparticipant Comparisons}

Correlations between ten factors affecting participation in educational endeavors and enrollment were computed separately for the four age categories and tabulated in Table 3, which considers age, sex, race, education, rural/urban, health, financial adequacy, general activity, self concept, and affect balance. These correlations are reviewed below under the headings of demographic characteristics, social well-being, and personal attitudes.

Demographic Characteristics. Age and prior educational attainment were demographic characteristics that showed the largest correlations to enrollment. However, except among the 
Table 3. Correlates of Enrollment, by Age

\begin{tabular}{|c|c|c|c|c|}
\hline \multirow{3}{*}{ Vartablo } & \multicolumn{4}{|c|}{ Pearson*s } \\
\hline & \multicolumn{4}{|c|}{ Age } \\
\hline & $18-24$ & $25-38$ & $40-5$ & $55 x+$ \\
\hline Ag* & $-0.23 * * *$ & -0.02 & $0.08 * *$ & $-0.10 * * *$ \\
\hline Sox & $-0.09 *$ & $-0.19 * * *$ & -0.05 & $0.07 *$ \\
\hline Bece & 0.01 & $-0.05 *$ & 0.02 & 0.02 \\
\hline Education & $0.30= \pm=$ & $0.30 \cdots \cdots$ & $0.15^{* * m}$ & $0.15 * * *$ \\
\hline Rural/Jrban & $-0.13^{*+*}$ & $-0.09 \%$ & $-0.07^{*}$ & $-0.08 * *$ \\
\hline Health & 0.00 & $0.07 * *$ & 0.02 & $0.07 * 4$ \\
\hline PInancial & $0.18 * m *$ & -0.04 & $0.09 * * *$ & $0.10 * * *$ \\
\hline Aetivity & $0.14^{m+*}$ & 0.02 & $-0.11 * * * 1 \%$ & $0.11 * * \cdots$ \\
\hline Self Concept & $0.11 \cdots$ & 0.02 & -0.01 & $0.11 * 4 *$ \\
\hline Affect Balance & 0.01 & $0.09 * * *$ & $-0.08 \% *$ & 0.03 \\
\hline (N) & $(742)$ & (1101) & $(1023)$ & $(1111)$ \\
\hline
\end{tabular}

youngest age category the substantive significance of age was not high. In most age categories it was the youngest who were more likely to be enrolled, the exception being among middle-aged people 40-55 years old, where the opposite was the case. Prior educational attainment proved to be the most important correlate of current enrollments, with this single variable explaining almost 10 percent of variance among both youth and young adult age categories.

Sex and rural/urban place of residence were both significant correlates of enrollment. More enrollments were found among males for youth, young adults, and middle-aged, and among females in the older age category. Rural/urban place of residence showed a significantly lower enrollment rate for rural residents across all age categories, in keeping with differential accessibility.

Race proved to be the weakest correlate of enrollment examined in this study, with no significant correlation to enrollment except among young adults, where a slightly higher enrollment rate among whites was evident.

Social Well-Being. Among three measures of social well-being, perceived adequacy of financial resources and a measure of 
general activity level were strongest correlates of enrollment. Although neither financial well-being nor general activity were significantly correlated to enrollment among young adults, significant correlations were found for all other age categories. In general, positive financial perceptions and higher activity levels were direct correlates of enrollment, but among the middle-aged it was the less active respondents who were more likely to be enrolled. The other measure of social well-being, health self-report, was a significant correlate of enrollment only among young adults and older people. In these categories the individuals with more positive health self-reports were also those more likely to be enrolled.

Personal Attitudes. Self concept (feeling old) and affect balance were both used as measures of personal attitude. Self concept proved to be a significant correlate of enrollment among youth and older people, but not among young adults or middle-aged. Precisely the opposite was the case for affect balance: only among young adults and middle-aged did affect balance appear as a significant correlate of enrollment.

\section{DISCUSSION}

Data from a large-scale national random sample have confirmed and elaborated many prior findings from smaller or geographically specialized samples. The facts that enrollment in any kind of educational endeavor is a decreasing function of age, and that the place of college-level enrollments among all enrollments is also a decreasing function of age, are both evident in these data. Both of these relationships appear to be related to the differences in educational attainment that distinguish the various age categories in American society, and which is the best single predictor of who is and who is not enrolled within any age category.

Age differences in reasons for enrollment are also correlated to age differentials in enrollment rates and place of enrollment. Among youth, young adults, and middle-aged the reasons given for enrollment are predominantly instrumental, although mixed instrumental and expressive motives are not uncommon. Among the oldest age category it is mixed motivation that is predominant, and purely instrumental motives are held by a substantial but smaller number of older people. Persons enrolled solely for expressive reasons represent only a small minority of any of the age categories analyzed, and it would appear 
that expressive needs alone are not usually sufficient to motivate enrollment.

In all adult age categories sampled the majority of people were not enrolled in educational endeavors. The chief barriers to enrollment were lack of time or lack of interest. Among the older population lack of time was less often a problem than in youth, young adulthood, or middle-age. Lack of interest was found to be a direct linear function of age, however. In contrast, dollar cost represented a more serious problem within youthful age categories, and was less likely to be cited as a barrier among middle-aged or older respondents.

Many significant differences between people enrolled and people not enrolled in further education were documented. Prior educational attainment was clearly the most distinct contrast, both overall and within any particular age category. Rural/urban differences were also evident, and although their effects were weaker than those of prior education they showed a consistent rural disadvantage across all age categories, young and old. Financial ability and general activity level also exhibited predictable effects, except that among middle-aged persons it was the less active who showed higher enrollment rates.

In general, the data show that it is a combination of variables including prior educational attainment, youthful self concept, positive health self-report, good financial ability, and other characteristics that explain who among older people-or any other age category-will enroll for further education. Affect balance (psychological well-being) and race do not make significant contributions to explaining variance in enrollments among older people in these data.

\section{CONCLUSION}

Findings from analysis of survey data from a large scale national random sample show important age-related variations in numbers of adult learners enrolled, places of enrollment, enrollment motives, and among nonparticipants, barriers to enrollment. Both numbers enrolled and the frequency of college or university enrollments (relative to enrollments in other educational settings) have been known to be decreasing functions of age. Mixed instrumental and expressive motives for enrollments in further education represent an important (but not necessarily predominant) pattern among all age categories, and these mixed motives are the predominant pattern for enrollments among older people, particularly in non-college settings. Instrumental motives for enrollment account for most enrollments 
among people in youthful and middle-age categories, particularly among those who are enrolled in college or university settings. The majority of persons in all adult age categories were nonparticipants in further education, and disinterest in education, poor health, and negative self-concept were more likely to be cited as barriers to enrollment by persons in mature age categories than by younger persons. In contrast, financial and time costs were more likely to be cited as barriers to enrollments by younger people than by older people.

The chief correlate of enrollments across all age categories was prior educational attainment, but many other significant correlates of enrollment such as being a "generally active" person were also found. Overall, correlates that were significant among older age categories, such as rural/urban, were usually significant among younger age categories as well. Among older people the "young-old," better eduated, urban, healthy, financially secure, and generally active people with youthful self-concepts were more likely than others to be enrolled in further educational endeavors.

\section{REFERENCES}

Bradburn, N. The structure of psychological well-being. Chicago: Aldine, 1969.

Campbell, R. T., Gardocki, G., Henretta, J. C., \& Paulig, C. Codebook for "The myth and reality of aging." Durham, N.C.: Duke University Medical Center, 1974.

Carp, A., Peterson, R., \& Roelfs, P. Adult learning interests and experiences. In K. P. Cross, J. R. Valley, \& associates (Eds.), Planning Non-Traditional Programs. San Francisco: Jossey-Bass, Inc., 1974.

Central Bureau for the Jewish Aged. Extending educational and cultural opportunities for older people. New York: Author, 1971.

DeCrow, R. Older Americans: New uses of mature ability. Washington, D.C.: American Association of Community and Junior Colleges, 1978.

Goodrow, B. A. Limiting factors in reducing participation in older adult learning opportunities, Gerontologist, 1975, 15, 418-422.

Graney, M. J. Happiness and social participation in aging. Journal of gerontology, 1975, 30, 701-706.

Graney, M. J. \& Hays, W. C. Senior students: Higher education after age 62, Educational gerontology, 1976, 1, 343-359.

Harris, L., \& associates. The myth and reality of aging in America. Washington, D.C.: The National Council on the Aging, Inc., 1975.

Hendrickson, A. How to work with older adults. In A. Hendrickson (Ed.), A manual on planning educational programs for older adults. Tallahassee: Florida State University, 1973. Pp. 124-133.

Hendrickson, A., \& Barnes, R. F. Educational needs of older people, Adult Leadership. $1967,16,2-4$.

Hiemstra, R. P. Continuing education for the aged, Adult Education, 1972, 22, 100-109. 
Jackson, M. \& Wood, J. L. Aging in America. Washington, D.C.: National Council on the Aging, 1976.

Londoner, C. A. Survival needs of the aged, International Journal of Aging and Human Development, 1971, 2, 113-117.

Marcus, E. E. Educational interests of the elderly as motives to seek out organized instruction. Washington, D.C.: Adult Education Association of the U.S.A. and ERIC Clearinghouse on Adult Education, 1967.

Michigan Policy and Program Analysis Division. The Michigan comprehensive plan on aging. Lansing: Michigan Office of Services to the Aging, 1975.

Peterson, D. A. The role of gerontology in adult education. In S. M. Grabowski \& W. D. Mason (Eds.), Education for the aging. Washington, D.C.: Adult Education Association of the U.S.A. and ERIC Clearinghouse on Adult Education, 1974. Pp. 41-60.

Phelps, L. W., Enderson, F. E., \& Peterson, W. A. Educational gerontology in Missouri. Kansas City, Missouri: Institute for Community Studies, 1976.

Racine County Planning Council. Racine County older adult comprehensive needs assessment. Racine, Wis.: Author, 1978.

Sarvis, R. E. Educational needs of the elderly. Washington, D.C.: U.S. Department of Health, Education and Welfare, 1973.

Timmermann, S. Lifelong learning and the older adult, Journal of the Institute for Socioeconomic Studies, 1978, 3, 19-27.

U.S. Bureau of the Census. Current Population Reports, P-20, Np. 80, 1958.

U.S. Bureau of the Census. Current Population Reports, P-23, No. 59, 1976.

Uphaus, R. M. Educating retirees, Adult Leadership, 1971, 16, 17-19.

Weinstock, R. The graying of the campus. New York: Educational Research Laboratories, 1978. 